\title{
Inventory of highly resolved temporal and spatial volatile organic compounds emission in China
}

\author{
J. Li, L. Y. Li, R. R. Wu, Y. Q. Li, Y. Bo \& S. D. Xie \\ State Key Joint Laboratory of Environmental Simulation and \\ Pollution Control, College of Environmental Sciences and Engineering, \\ Peking University, PR China
}

\begin{abstract}
Volatile organic compounds (VOCs) in the atmosphere play significant roles in secondary organic aerosol (SOA) and ground-level ozone $\left(\mathrm{O}_{3}\right)$ formation. Emission inventories of biogenic VOCs (BVOCs) and anthropogenic VOCs (AVOCs) for 2013 in China were developed at a spatial resolution of $36 \mathrm{~km} \times 36 \mathrm{~km}$. The monthly emission inventory of BVOCs were established using MEGAN2.1 driven by WRF model, based on the most detailed statistical data and the Vegetation Atlas of China. The emission inventory of AVOCs were established based on statistical data, literature surveyed and model calculated emission factors. The results showed that the total annual BVOC emissions in 2013 were $53.51 \mathrm{Tg}$, including $32.23 \mathrm{Tg}$ isoprene, $6.10 \mathrm{Tg}$ monoterpene, $1.23 \mathrm{Tg}$ sesquiterpene, and $13.96 \mathrm{Tg}$ other VOCs. BVOC emissions from broadleaf trees contributed almost half to the total emissions. Broadleaf trees were the largest contributors to isoprene. The emissions of AVOCs from China in 2013 were $31.02 \mathrm{Tg}$. Solvent utilization, transportation, industrial processes, biomass burning and fossil fuel combustion generated $10.18 \mathrm{Tg}, 7.96 \mathrm{Tg}, 7.65 \mathrm{Tg}, 3.00 \mathrm{Tg}$, and $2.22 \mathrm{Tg}$ of VOCs, respectively. Passenger cars, petroleum refining, coke production, field burning of biomass, and raw chemical manufacturing were the primary AVOC sources nationwide. In central eastern China, the estimated biogenic emissions of VOCs were very small, and the anthropogenic emissions of VOCs were dominant in this region. However, in northeastern, and southern China, there are relatively large biogenic emissions of VOCs, leading to an important impact on the ozone production in these regions.
\end{abstract}

Keywords: emission inventory, biogenic VOCs, anthropogenic VOCs. 


\section{Introduction}

As the largest developing country in Asia, China has suffered from serous air pollution, and the formation processes are very complex. Besides the primary pollutants emitted directly, China air quality is more seriously affected by fine particles and photochemical smog formed in secondary reactions. Research on atmospheric aerosols show that organics are the major components in fine particle such as fine particles $\left(\mathrm{PM}_{2.5}\right)$ in China. Volatile organic compounds (VOCs) play important roles in these reactions because they can be photo chemically oxidized to form a variety of secondary pollutants such as ground-level ozone $\left(\mathrm{O}_{3}\right)$ and secondary organic aerosols (SOAs) (Seinfeld and Pandis [1]). Moreover, certain persistent VOCs like chlorinated species are stratospheric $\mathrm{O}_{3}$ depletors (Atkinson and Arey [2]), and some VOCs species are air toxins that can significantly affect human health and welfare.

Studies of $\mathrm{NO}_{\mathrm{X}}$ and VOCs-limited regimes of $\mathrm{O}_{3}$ production were conducted by Chinese researchers in the Pearl River Delta, Yangtze River Delta and the Beijing area, where $\mathrm{O}_{3}$ pollution episodes frequently occur (Li et al. [3]). Their results showed that $\mathrm{O}_{3}$ formation was controlled by ambient VOCs in these regions, and the control of photochemical $\mathrm{O}_{3}$ can be largely due to a concerted reduction of VOCs and NOx emissions. In this regard, the establishment of reliable VOCs emission inventories, for current and future years is essential to develop a strategy to reduce VOCs emissions.

VOCs can be directly emitted into the atmosphere from both biogenic and anthropogenic sources, and they may also be formed as products of the photochemical oxidation of other VOC species. On a global scale, natural emissions are the most important VOC sources (Atkinson and Arey [2]), and the most important emitter is vegetation, especially forest ecosystems (Guenther et al. [4]). Because of their high reactivity, biogenic volatile organic compounds (BVOCs) are the largest source of secondary organic carbon aerosols (SOCs), with the most important precursor compound being isoprene, followed by monoterpene in China ( $\mathrm{Fu}$ et al. [5]). However, anthropogenic VOCs (AVOCs) emissions dominate in the total emissions on the urban and regional scale (Li et al. [6]). Research on the source and emission characteristics of VOCs has been an important issue in atmospheric chemistry studies. Identification of emission sources and quantification of source contributions to ambient air pollutants are prerequisite for the formulation and implementation of air pollution control measures and strategies.

Emission inventory is a widely used method to calculated national and global emissions of VOCs. Characterization and quantification of VOC emissions including their spatiotemporal characteristics are of great uncertainty due to complex and diversified emission sources. In this study, emission inventories of BVOCs and AVOCs for 2013 in China were developed at a spatial resolution of $36 \mathrm{~km} \times 36 \mathrm{~km}$. 


\section{Methodology}

\subsection{BVOC emission estimation}

The emissions of BVOCs in China were estimated using NEGANv2.1 (http://acd.ucar.edu/ guenther/MEGAN/MEGAN.htm). MEGAN has been proved to be an advanced global and regional biogenic emission model to estimate the net emission rates of BVOCs and other natural gases into the above-canopy atmosphere (Guenther et al. [7]). In this study, biogenic emissions of 141 chemical species were simulated, including isoprene, 37 monoterpenes, 32 sesquiterpenes, and 71 OVOCs. The data inputted into the MEGAN model includes plant functional type (PFT) distribution, emission factors and weather data. Detail method can be seen in Li et al. [8].

\subsection{AVOC emission estimation}

Anthropogenic VOC emissions were estimated using the "emission factor method". The emission sources were classified into a total of five sources of transportation, stationary fossil fuel combustion, biomass burning, industrial processes and solvent utilization, according to the actual situation of AVOCs emissions in China. "Emission factor method" were used to estimate the emissions of AVOCs. The emission estimation of each AVOCs sources were initially estimated at the provincial level by multiplying the annual average corresponding activities and detailed emission factors, as shown in eqn (1). Vehicular emissions were calculated based on the emission factors, the population of vehicles, and the corresponding annual average mileage traveled for each vehicle category. The emission estimation of other sources was based on annual average rates of emission related activities, detailed emission factors. Thus, the total AVOCs emissions were estimated by eqn (1).

$$
E_{m}=\sum P_{m, i, j} \times V M T_{i, j} \times E F_{i, j}+\sum A_{m, k} \times E F_{k}
$$

where $E m$ is the AVOCs emission (Tg) in province $m(\mathrm{Tg})$. For vehicular emissions, $P_{m, i, j}$ is the population of vehicles in category $i$ under emission standard $j$ in province $m ; V M T_{i, j}$ is the annual average mileage (kilometers) for vehicular in category $i$ under emission standard $j ; E F i, j$ is the emission factor $(\mathrm{g} / \mathrm{km})$ of vehicles for vehicular in category $i$ under emission standard $j$. For the other sources excluding vehicles, $A m, i$ is the activity rate of source $k$ in province $m$; and $E F i$ is the emission factor of source $i$.

The source-specific activity data required by the AVOCs emission inventory were obtained from the provincial statistical yearbooks covering 31 province, autonomous regions and municipalities in China excluding Hong Kong, Taiwan and Macau. The VOCs emission factors of anthropogenic sources excluding vehicles were mainly obtained from locally measured emission factors, recently published literatures, EPA AP42 Report (http://www3.epa.gov/ttnchie1/ap42/) and EEA Air Pollutant Emission Inventory Guidebook 2013 EEA [9]. Emission 
factors of vehicular emissions were calculated by COPERT IV, a widely used program for the estimation of the emission factor for vehicles in Europe. The detailed emission factors and activity data used in this study can be seen from $\mathrm{Wu}$ et al. [10].

\section{Results and discussion}

\subsection{The emission inventory of BVOCs}

An emission inventory of BVOCs in China for the year 2013 at a high spatial and temporal resolution of $36 \mathrm{~km} \times 36 \mathrm{~km}$ and $1 \mathrm{~h}$ was established, based on the most detailed and accurate current vegetation investigations. The total annual BVOC emissions in 2013 were $55.88 \mathrm{Tg}$, including $33.87 \mathrm{Tg}$ isoprene, $6.36 \mathrm{Tg}$ monoterpene, $1.29 \mathrm{Tg}$ sesquiterpene, and $14.37 \mathrm{Tg}$ OVOCs. $\alpha$-Pinene and $\beta$-pinene were the largest contributors to the total monoterpene emissions, farnesene and caryophyllene contributed the most to sesquiterpene emissions. BVOC emissions from broadleaf trees contributed almost half to the total emissions. Broadleaf trees (mainly Quercus, bamboo, Populus) were the largest contributors to isoprene, needle leaf trees (mainly Pinus massoniana) contributed the most to monoterpene and sesquiterpene, crop (mainly rice) was the largest contributor to OVOCs. Broadleaf trees and shrubs mainly emitted isoprene, needle leaf trees generated more OVOCs and monoterpene, grasslands and crops mainly emitted OVOCs.

The distribution of isoprene emission fluxes was consistent with the distribution of broadleaf trees, especially tree species with high or higher emission potential. The spatial distribution of annual emissions of BVOCs for China is shown in fig. 1. Fluxes were highest in Da Hinggan and Xiao Hinggan, Changbai

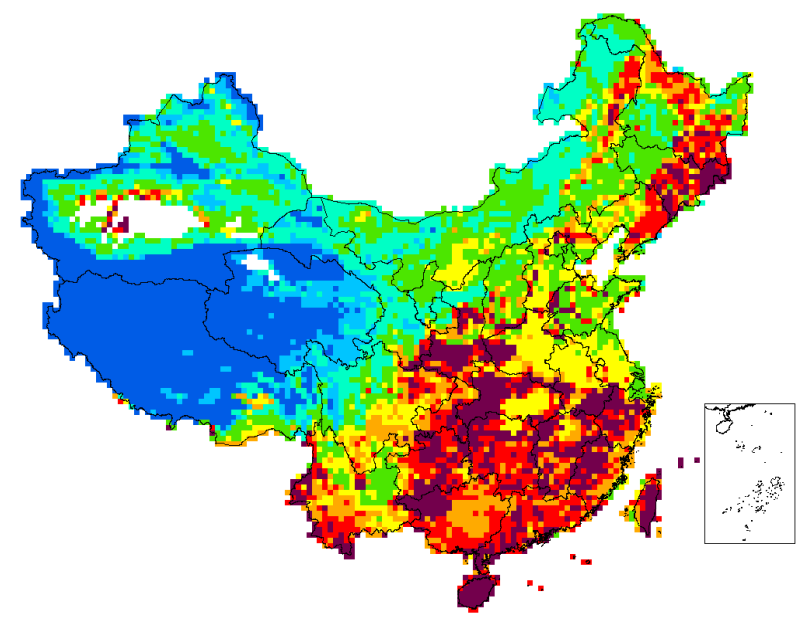

Figure 1: The spatial distribution of annual emissions of BVOCs for China at a resolution of $36 \mathrm{~km} \times 36 \mathrm{~km}$. 
Mountains, the Qinling area, southeastern China, southwestern forest regions, and Hainan and Taiwan provinces, with values of $>5$ tons $\mathrm{km}^{-2} \mathrm{yr}^{-1}$ and some even $>12$ tons $\mathrm{km}^{-2} \mathrm{yr}^{-1}$. Due to sparse distribution of vegetation and lower temperature, Tibet and Qinghai provinces had the lowest isoprene emission flux $\left(<50 \mathrm{~kg} \mathrm{~km}^{-2} \mathrm{yr}^{-1}\right)$. Monoterpene and sesquiterpene emission fluxes were relatively lower than isoprene, which were the highest in southern China. Southern China also had the highest OVOC emissions.

Strong seasonal and diurnal patterns for BVOC emissions in China were caught (fig. 2.). The highest BVOC emissions occurred in summer (35.84 Tg) and the lowest in winter $(1.34 \mathrm{Tg})$. BVOC emissions at daytime were much higher than during the night, and peaked at noon. Isoprene emissions had the strongest seasonal and diurnal patterns.

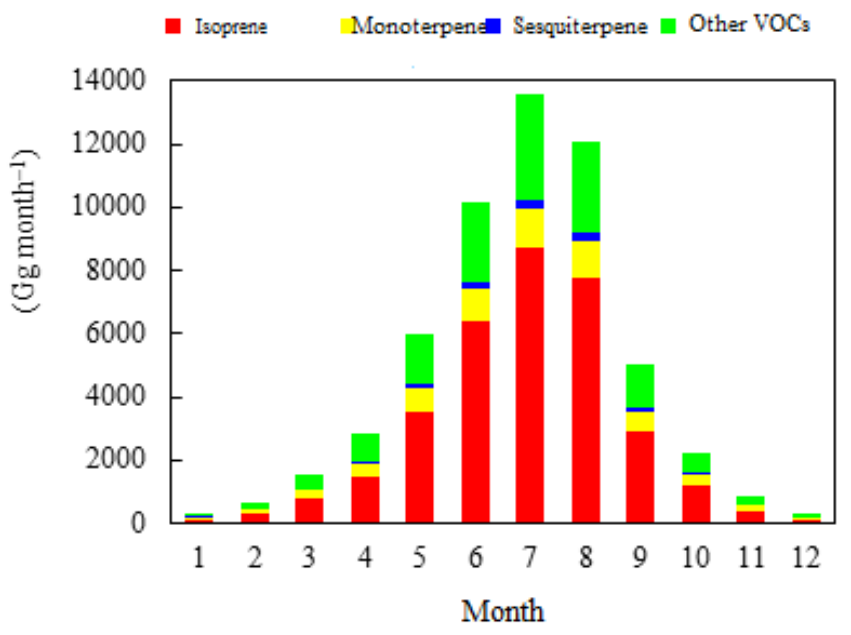

Figure 2: Monthly BVOC emissions in China.

\subsection{Emission inventory of AVOCs}

The total VOC emissions in China were $31.02 \mathrm{Tg}$ in 2013. Solvent utilization, transportation and Industrial processes were the three largest VOC sources, accounting for $32.8 \%, 25.7 \%$, and $24.7 \%$ of the total emissions. Biomass burning and stationary fossil fuel combustion contributed $9.7 \%$ and $7.2 \%$ of the total, respectively. To better identify the spatial characteristics of anthropogenic, VOC emissions in China, the emission inventory were plotted at a resolution of $36 \mathrm{~km} \times 36 \mathrm{~km}$ using ArcGIS (fig. 3). Emissions of China's AVOC had remarkable spatial characteristics, with emissions in the eastern coastal region being much larger than those in the western inland. The most polluted areas were mainly centered in the Bohai Economic Rim, the Yangtze River Delta, the Pearl River Delta, and the Sichuan Basin, which are the most developed and industrialized regions in China. In contrast, the western area, consisting of Tibet Autonomous 
Region, Qinghai Province, Xinjiang Uygur Autonomous, and Inner Mongolia, which occupies over half of the territory, only contributed $5.8 \%$ of the total emissions. The tremendous differences in VOC emissions among different regions were consistent with the unbalanced economic development in China.
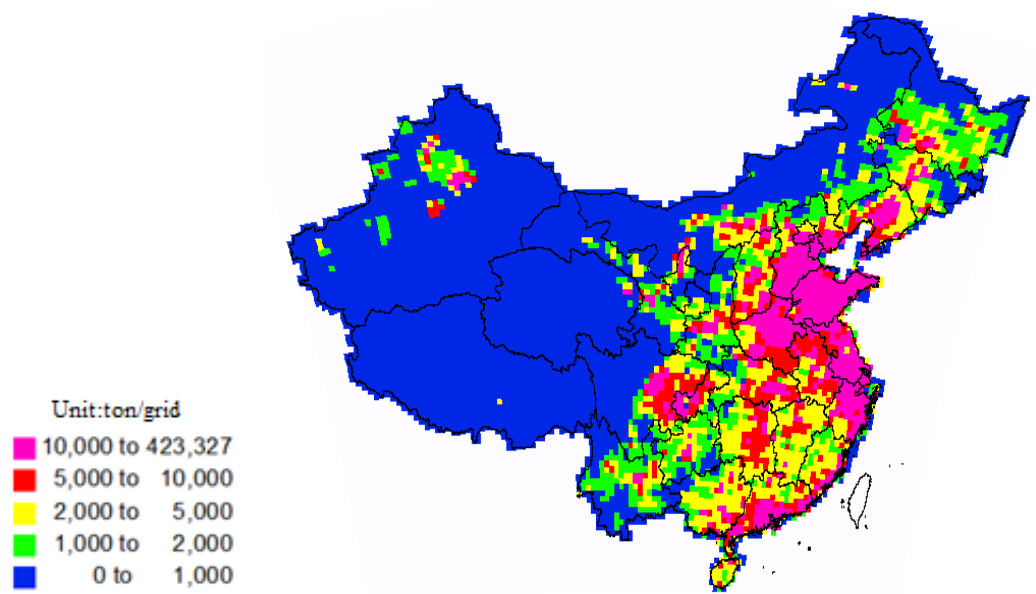

Figure 3: The spatial distribution of annual emissions of AVOCs for China at a resolution of $36 \mathrm{~km} \times 36 \mathrm{~km}$.

\subsection{Total VOC emissions}

The total VOC emissions in China 2013 were $84.53 \mathrm{Tg}$, including 53.51Tg BVOCs and 31.02 Tg AVOCs. The VOCs emissions in each province were listed in Table 1. The ratio between AVOC emissions to BVOC emissions in each province was significant different. The BVOC emissions account for about $65 \%$ of total VOCs emissions in China. However, in many economically developed provinces, the estimated biogenic emissions of VOCs were very small, and the anthropogenic emissions of VOCs were dominant in this region.

\section{Conclusions}

Chinese BVOC emission inventories at a spatial resolution of $36 \mathrm{~km} \times 36 \mathrm{~km}$ were established for the year 2013. In central eastern China, the estimated biogenic emissions of VOCs were very small, and the anthropogenic emissions of VOCs were dominant in this region. However, in northeastern, and southern China, there are relatively large biogenic emission of VOCs, leading to an important impact on the ozone production in these regions. 
Table 1: VOC emissions in each province (Unit: Gg).

\begin{tabular}{|c|c|c|c|c|}
\hline Province & TVOC & AVOC & BVOC & $\mathrm{A} \%$ \\
\hline Guangdong & 6054 & 2552 & 3502 & $42.1 \%$ \\
\hline Guangxi & 4752 & 795 & 3957 & $16.7 \%$ \\
\hline Jiangxi & 4380 & 692 & 3688 & $15.8 \%$ \\
\hline Hubei & 4305 & 1172 & 3134 & $27.2 \%$ \\
\hline Hunan & 4266 & 1048 & 3218 & $24.6 \%$ \\
\hline Shandong & 4199 & 3015 & 1184 & $71.8 \%$ \\
\hline Henan & 4085 & 1851 & 2234 & $45.3 \%$ \\
\hline Zhejiang & 3933 & 2078 & 1855 & $52.8 \%$ \\
\hline Yunnan & 3847 & 650 & 3197 & $16.9 \%$ \\
\hline Inner Mongolia & 3574 & 779 & 2795 & $21.8 \%$ \\
\hline Heilongjiang & 3431 & 961 & 2470 & $28.0 \%$ \\
\hline Fujian & 3409 & 973 & 2436 & $28.5 \%$ \\
\hline Sichuan & 3389 & 1300 & 2089 & $38.4 \%$ \\
\hline Shaanxi & 3345 & 731 & 2614 & $21.8 \%$ \\
\hline Anhui & 3072 & 1071 & 2001 & $34.9 \%$ \\
\hline Jilin & 2937 & 719 & 2218 & $24.5 \%$ \\
\hline Guizhou & 2783 & 359 & 2424 & $12.9 \%$ \\
\hline Jiangsu & 2745 & 2309 & 437 & $84.1 \%$ \\
\hline Hebei & 2681 & 1833 & 848 & $68.4 \%$ \\
\hline Liaoning & 2504 & 1543 & 961 & $61.6 \%$ \\
\hline Xinjiang & 1988 & 628 & 1360 & $31.6 \%$ \\
\hline Shanxi & 1494 & 756 & 738 & $50.6 \%$ \\
\hline Hainan & 1433 & 203 & 1231 & $14.2 \%$ \\
\hline Chongqing & 1392 & 455 & 938 & $32.6 \%$ \\
\hline Gansu & 1189 & 416 & 773 & $35.0 \%$ \\
\hline Shanghai & 774 & 763 & 12 & $98.5 \%$ \\
\hline Tibet & 709 & 29 & 680 & $4.0 \%$ \\
\hline Tianjin & 666 & 633 & 33 & $95.0 \%$ \\
\hline Beijing & 575 & 462 & 113 & $80.4 \%$ \\
\hline Qinghai & 384 & 101 & 283 & $26.2 \%$ \\
\hline Ningxia & 238 & 146 & 92 & $61.4 \%$ \\
\hline Total & 84533 & 31019 & 53515 & $36.7 \%$ \\
\hline
\end{tabular}

\section{Acknowledgement}

This study was funded by the Natural Science Foundation key project (grant no. 91544106).

\section{References}

[1] Seinfeld, J. H. \& Pandis, S. N., Atmospheric chemistry and physics: From air pollution to climate change, 2nd Edn, Wiley Interscience, Hoboken, US, 2006. 
[2] Atkinson, R. \& Arey, J., Atmospheric degradation of volatile organic compounds. Chem. Rev., pp. 4605-4638, 2003.

[3] Li, L., Xie, S., Zeng, L., Wu, R. \& Li, J., Characteristics of volatile organic compounds and their role in ground-level ozone formation in the BeijingTianjin-Hebei region, China, Atmospheric Environment, 113, pp. 247-254, 2015.

[4] Guenther, A., Hewitt, C.N., Erickson, D., Fall, R., Geron, C., Graedel, T., Harley, P., Klinger, L., Lerdau, M., McKay, W.A., Pierce, T., Scholes, B. \& Steinbrecher, R., A global-model of natural volatile organic-compound emissions. Journal of Geophysical Research-Atmospheres, 100, pp. 88738892, 1995.

[5] Fu, T. M., Cao, J. J., Zhang, X.Y., Lee, S.C., Zhang, Q., Han, Y.M., Qu, W.J., Han, Z., Zhang, R., Wang, Y.X., Chen, D. \& Henze, D.K. Carbonaceous aerosols in China: top-down constraints on primary sources and estimation of secondary contribution, Atmos. Chem. Phys., 12, pp. 2725-2746, 2012.

[6] Li, J., Xie, S.D., Zeng, L.M., Li, L.Y., Li, Y.Q. \& Wu, R.R., Characterization of ambient volatile organic compounds and their sources in Beijing, before, during, and after Asia-Pacific Economic Cooperation China 2014, Atmospheric Chemistry and Physics, 15, pp. 12453-12490, 2015.

[7] Guenther, A., Jiang, X., Heald, C.L., Sakulyanontvittaya, T., Duhl, T., Emmons, L.K. \& Wang, X., The Model of Emissions of Gases and Aerosols from Nature version 2.1 (MEGAN2.1): an extended and updated framework for modeling biogenic emissions. Geoscientific Model Development, 5, pp. 1471-1492, 2012.

[8] Li, L \& Xie, S., Historical variations of biogenic volatile organic compound emission inventories in China, 1981-2003, Atmospheric Environment, 95, pp. 185-196, 2014.

[9] EEA, Air Pollutant Emission Inventory Guidebook. EEA technical Report No. 12, 2013 EP and CEU, 2013.

[10] Wu, R., Bo, Y., Li, J., Li, L., Li, Y. \& Xie, S., Method to establish the emission inventory of anthropogenic volatile organic compounds in China and its application in the period 2008-2012, Atmospheric Environment, 127, pp. 244-254, 2016. 